\title{
SOBRE A VIOLÊNCIA CULTIVADA NO JARDIM
}

\section{Rodrigo Freitas*}

“Fomos maus expectadores da vida se não vemos também a mão que delicadamente - mata!"

\section{Nietzsche}

As pinturas que compõem o livro intitulado Sobre a violência cultivada no jardim são fruto de uma pesquisa artística que se interessa pelas formas veladas de violência. Não é por acaso que a casa, com seus objetos e arredores, fornece a matéria prima para a realização desse trabalho, no qual o espaço doméstico se torna palco para as tensões e equilíbrios instáveis que permeiam as relações cotidianas. Sobre a violência cultivada no jardim é um trabalho que dialoga com o as artes plásticas e, de maneira especial, com o cinema, do qual derivam muitas das imagens desse livro de pinturas. Desse diálogo entre as artes, as referências se entrecruzam, se ampliam, permitindo a construção de novas leituras para cada imagem, que, silenciosamente, deixa entrever a violência coerciva presente, sobretudo, no contexto familiar.

Rodrigo Freitas é bacharel em Artes pela Universidade Federal de Minas Gerais, onde atualmente desenvolve pesquisa de doutorado. Em 2012, participou do Programa Independente da Escola São Paulo e Integrou o IV Programa Bolsa Pampulha em Belo Horizonte. Teve participação em algumas mostras, entre elas: $39^{\circ}$ SARP, Entretempos, Bolsa Pampulha, Exposição PIESP Instituto Cervantes.

rodrigofreitasrodrigues@gmail.com 


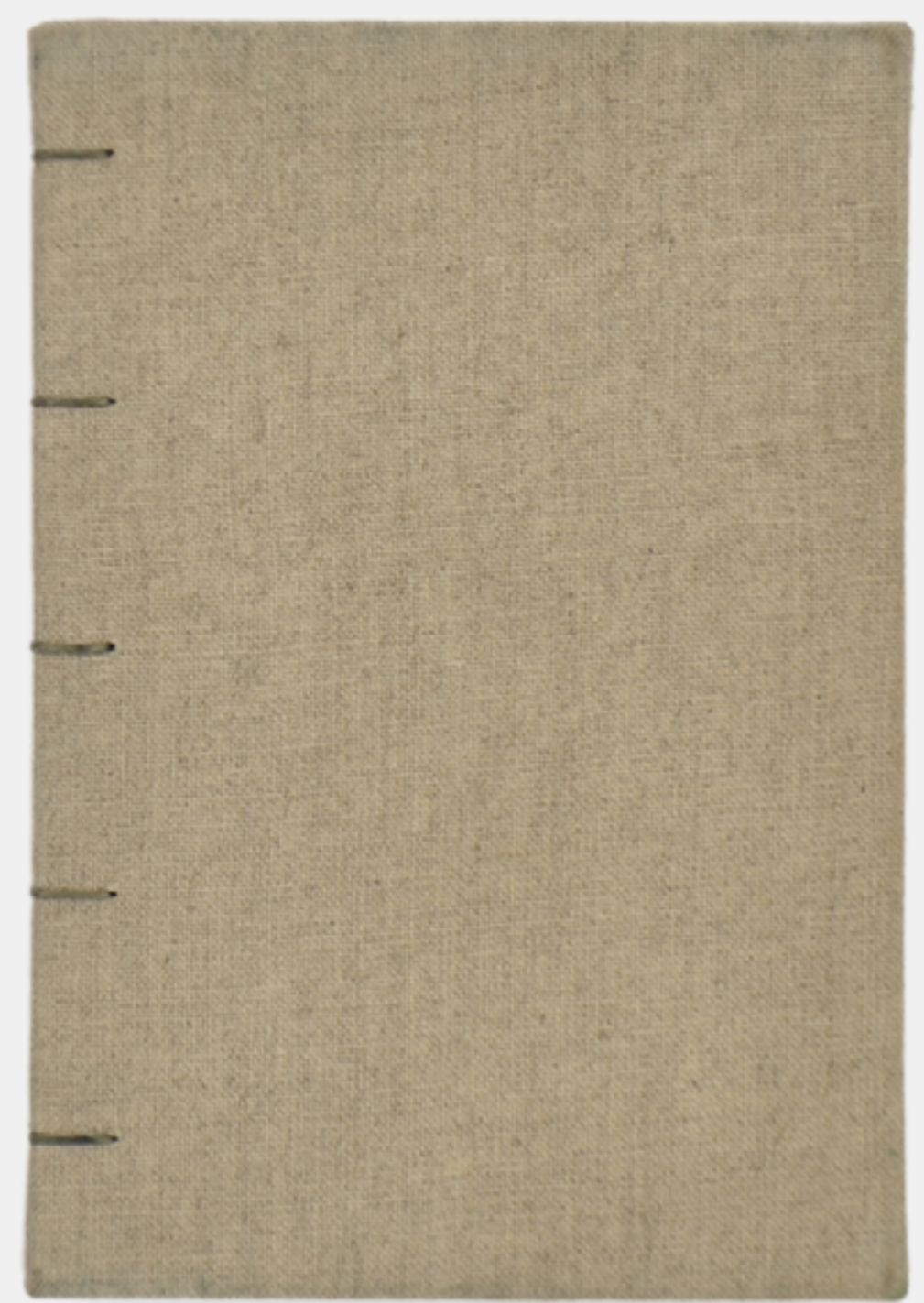

Poéticas 


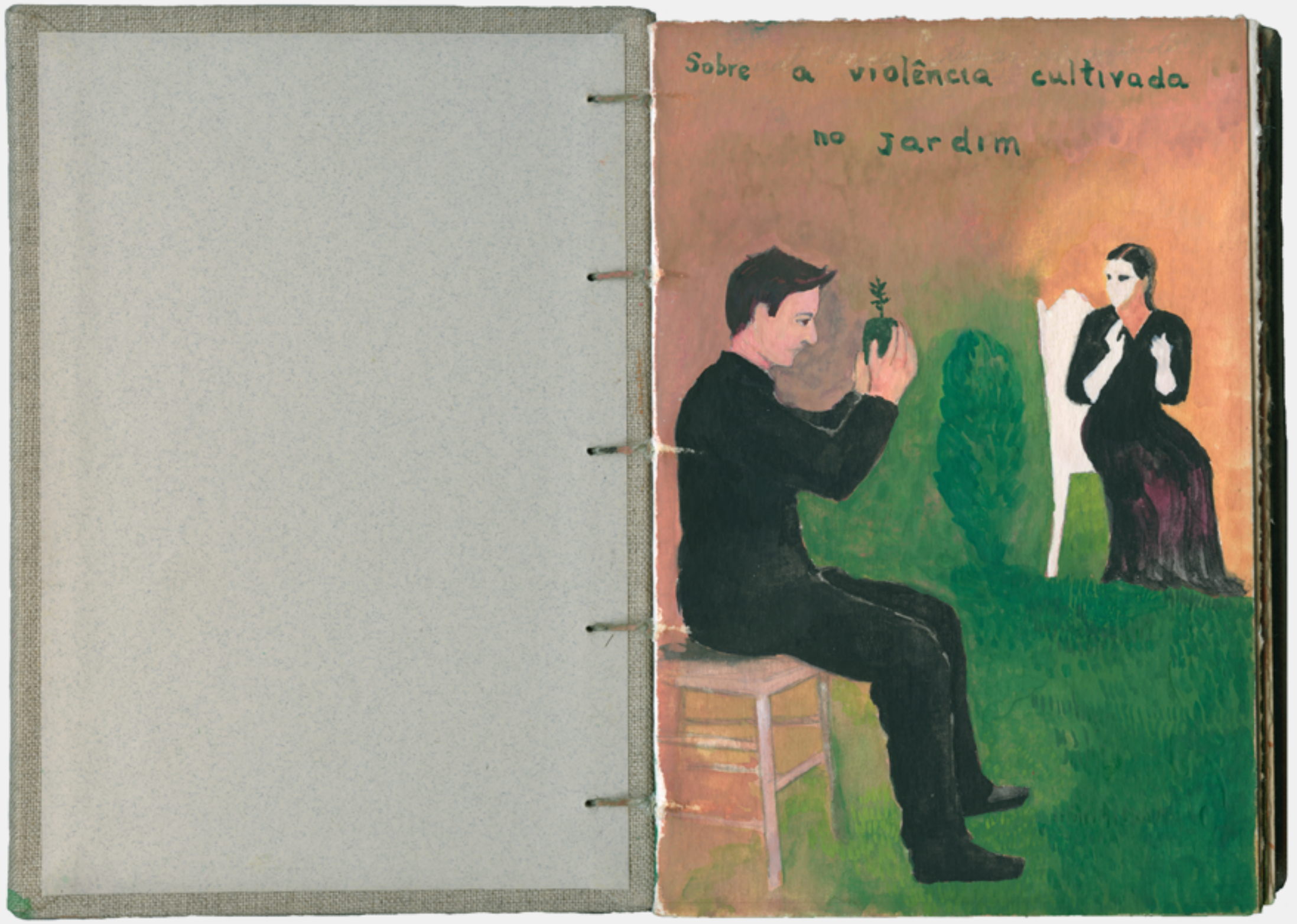

2013

Guache sobre papel $15 \times 21 \mathrm{~cm}$ 


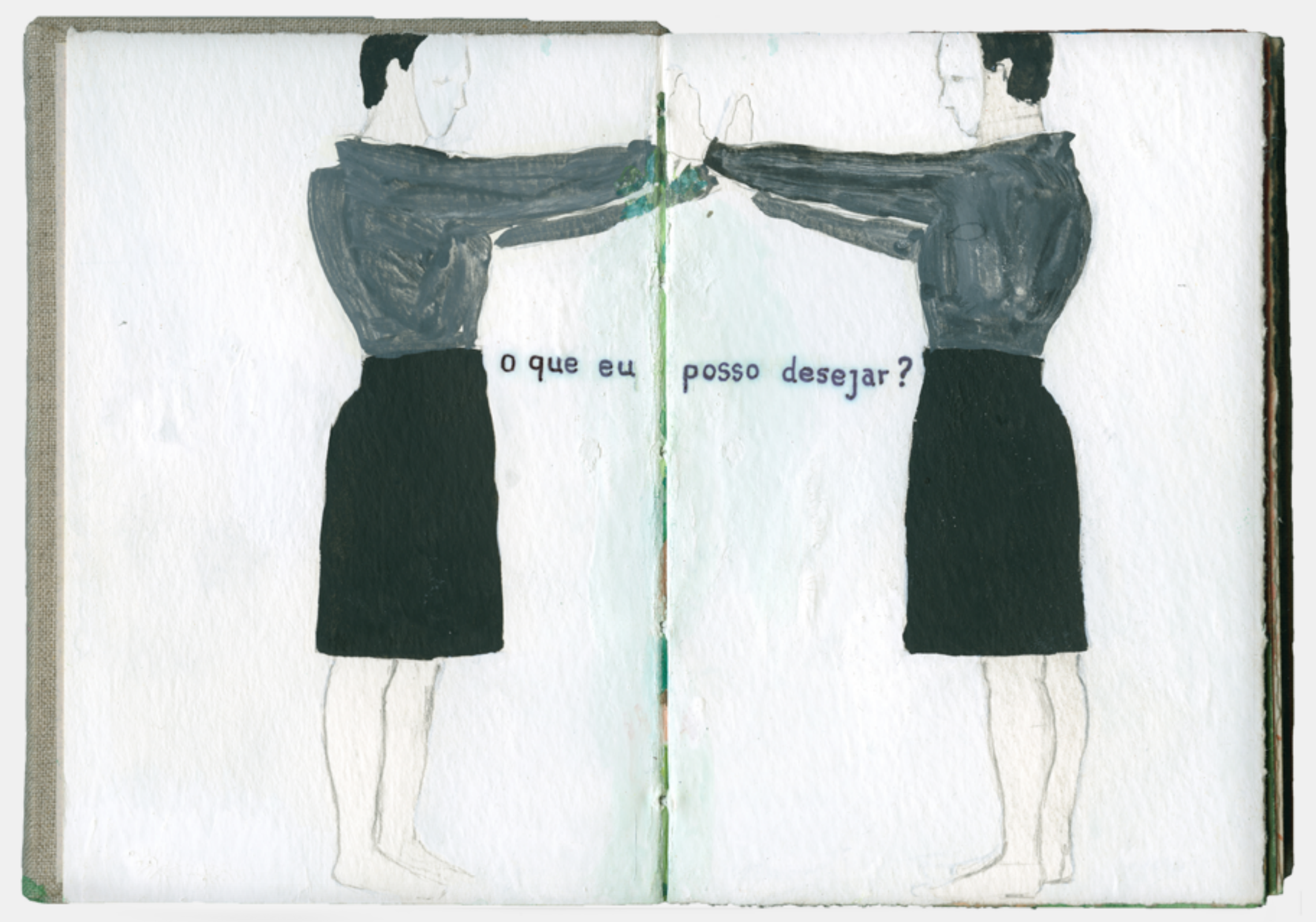

2013

Guache sobre papel $15 \times 21 \mathrm{~cm}$ 


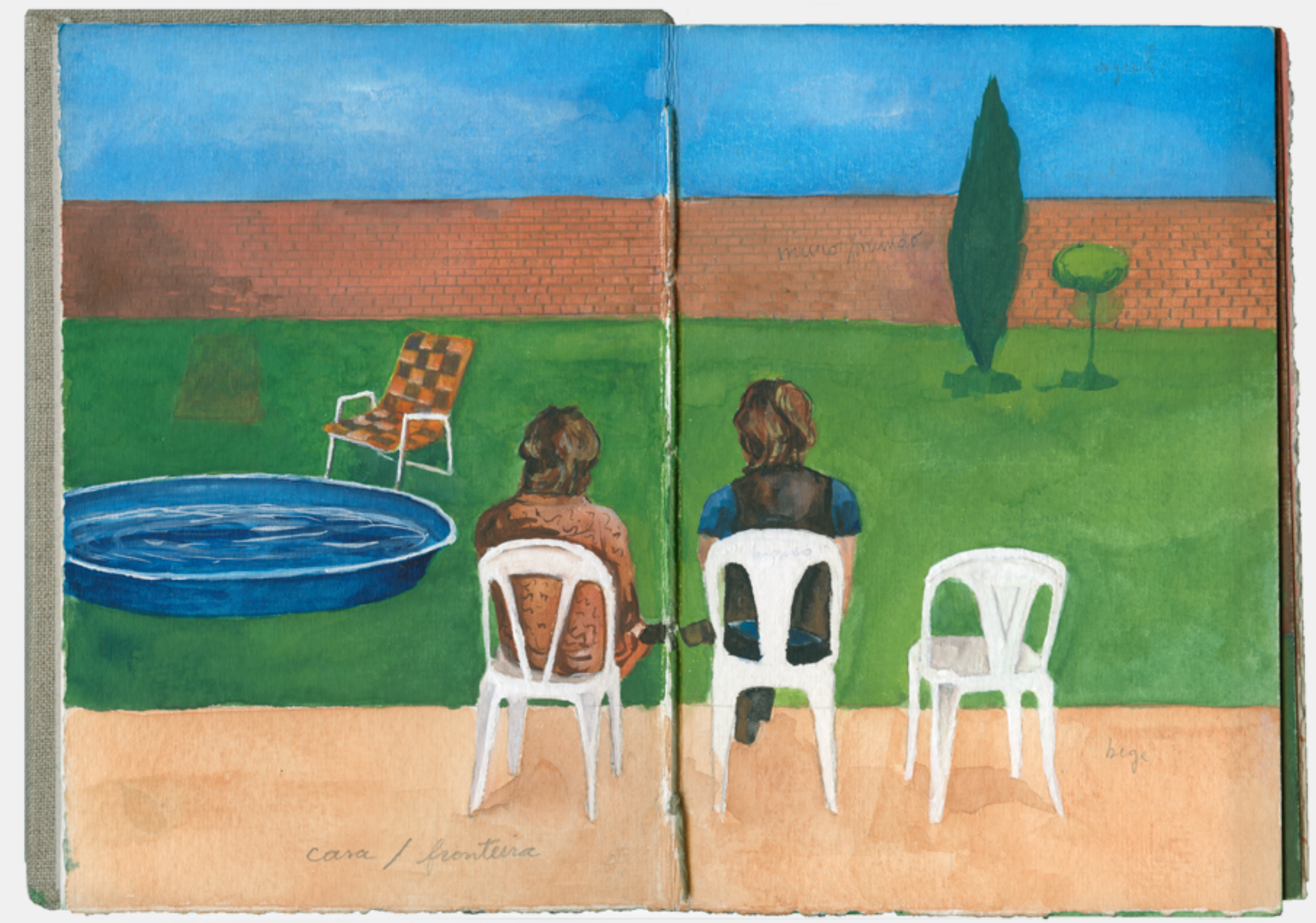

2013

Guache sobre papel $15 \times 21 \mathrm{~cm}$ 


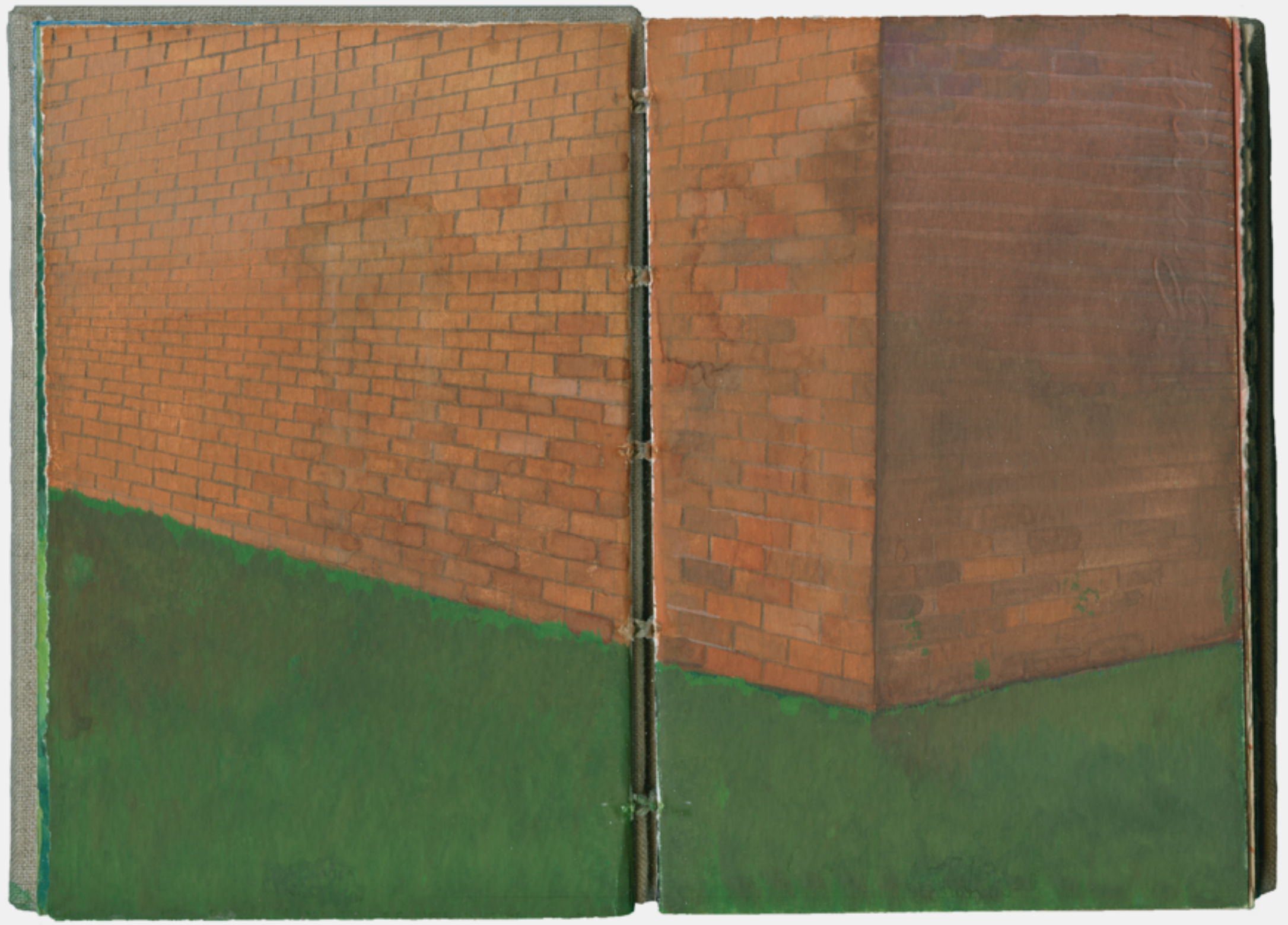

2013

Guache sobre papel

$15 \times 21 \mathrm{~cm}$ 


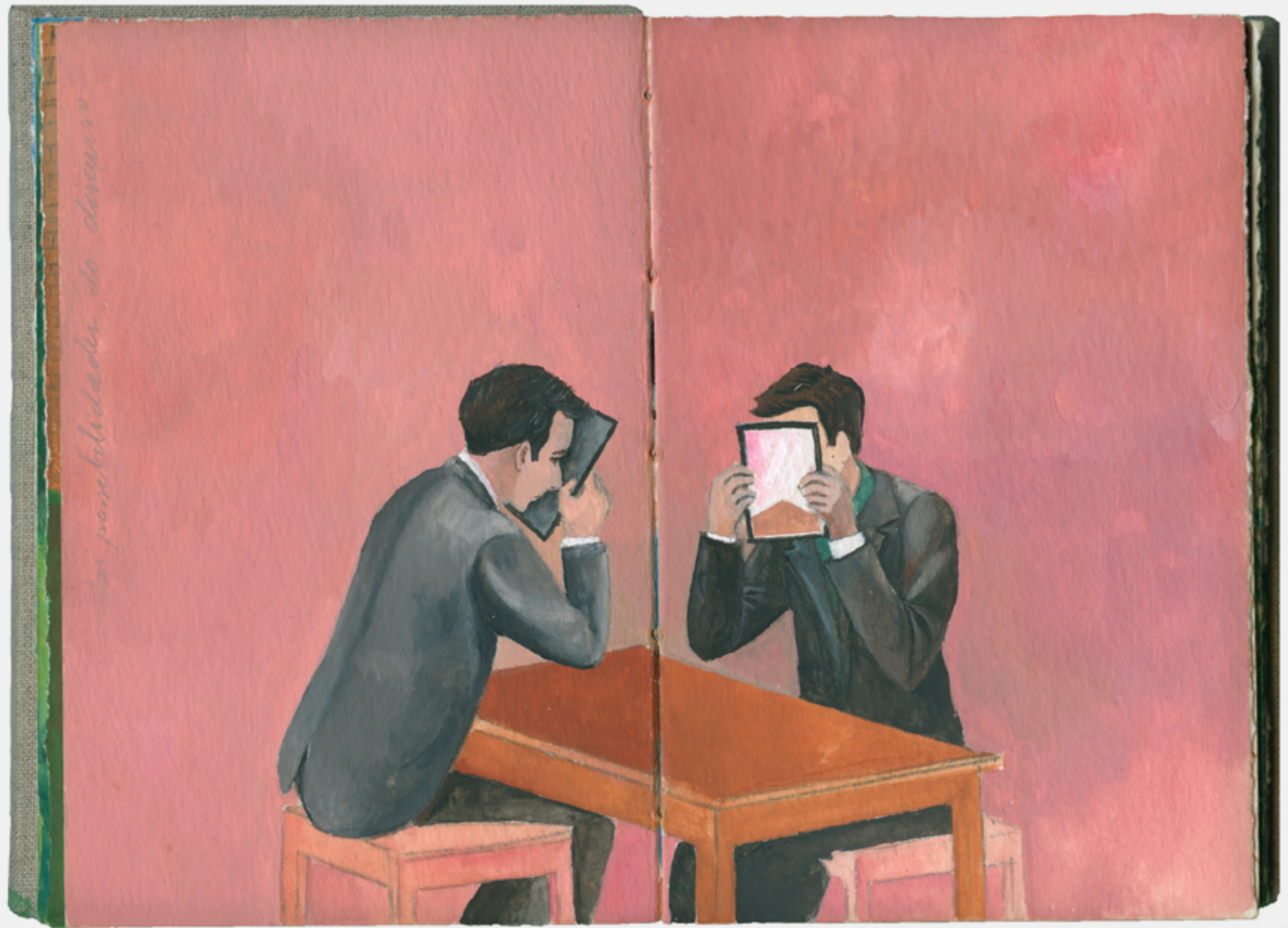

2013

Guache sobre papel

$15 \times 21 \mathrm{~cm}$ 


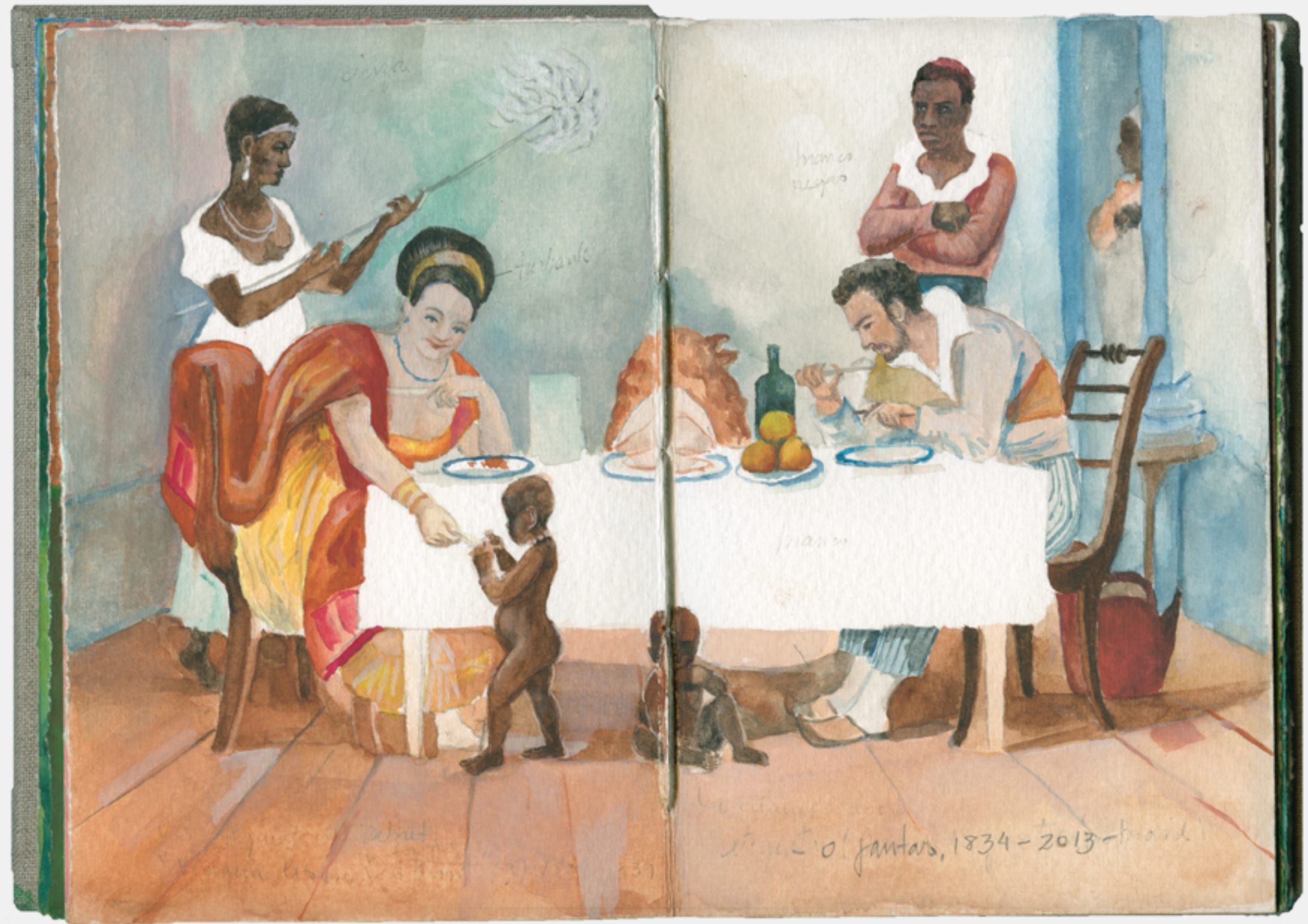

2013

Guache sobre papel

$15 \times 21 \mathrm{~cm}$ 


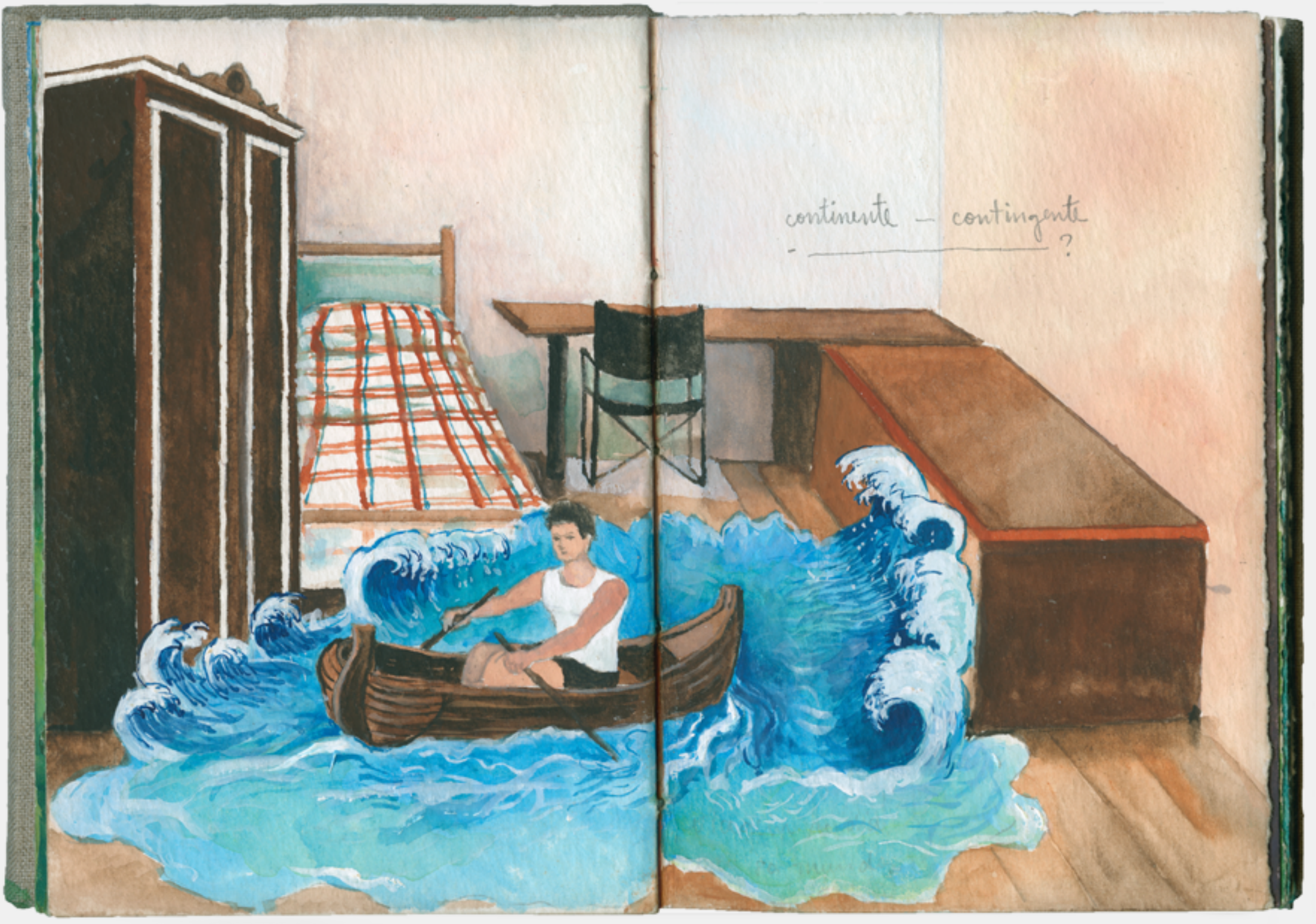

2013

Guache sobre papel 


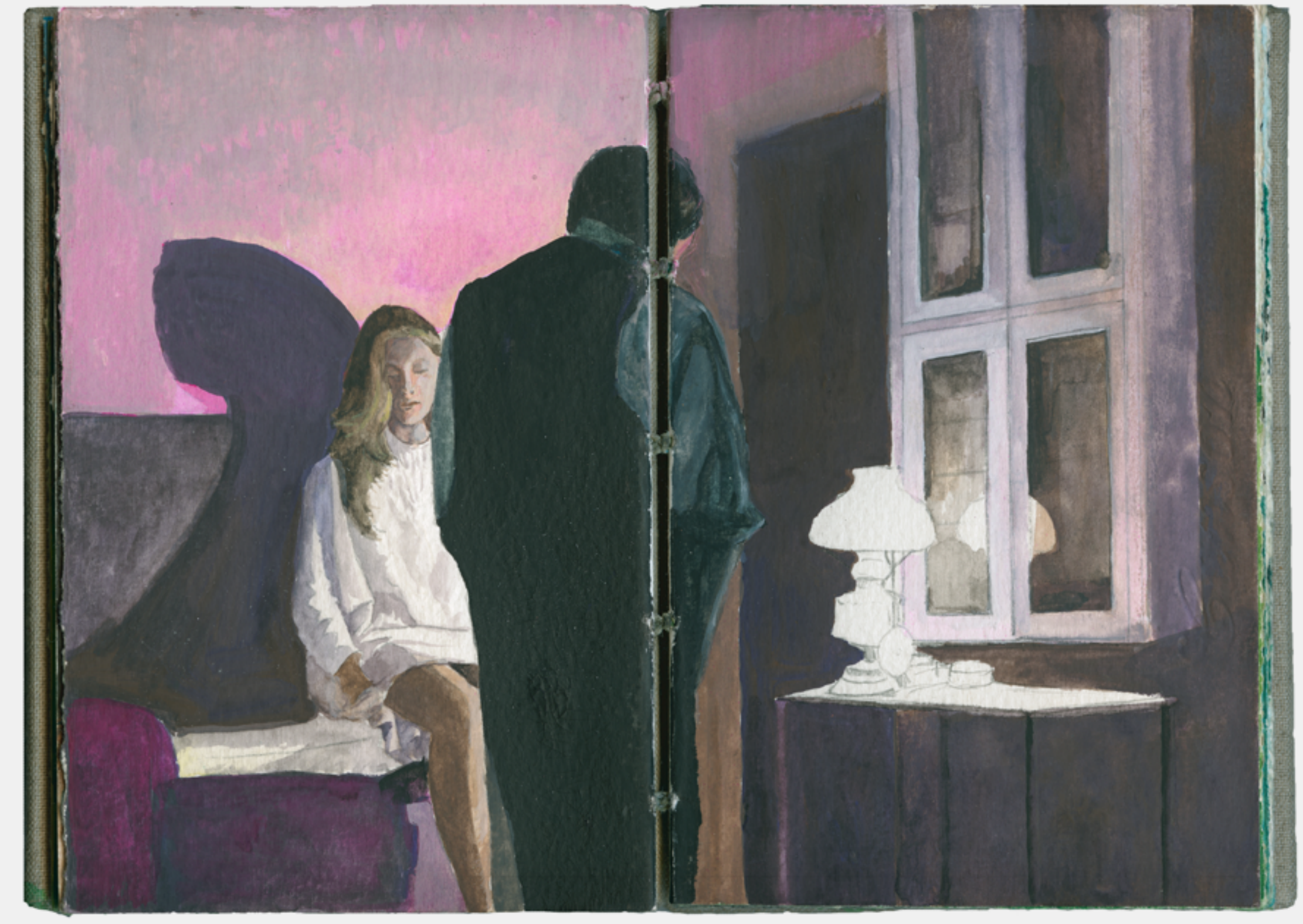

2013

Guache sobre papel $15 \times 21 \mathrm{~cm}$ 


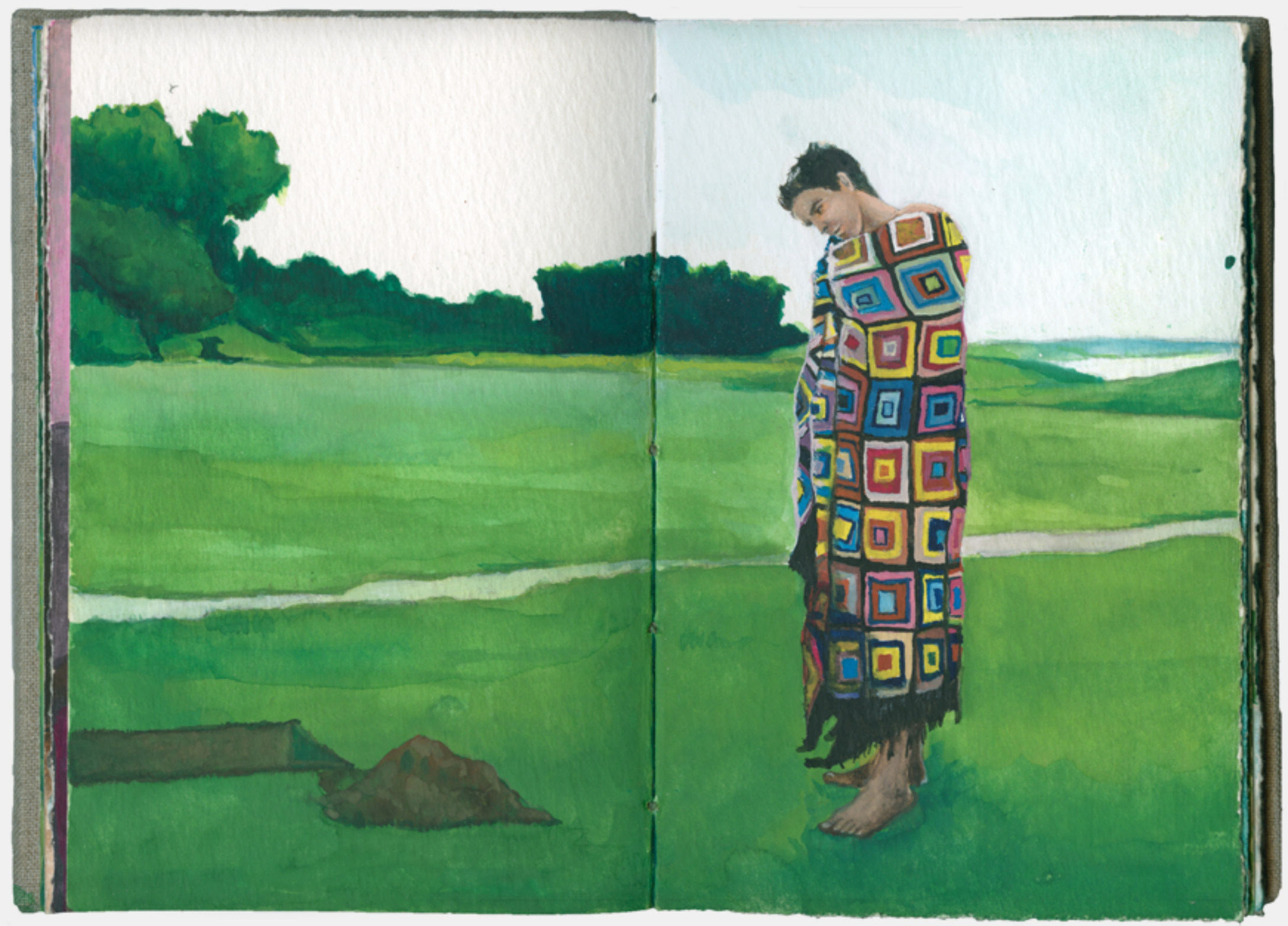

2013

Guache sobre papel 


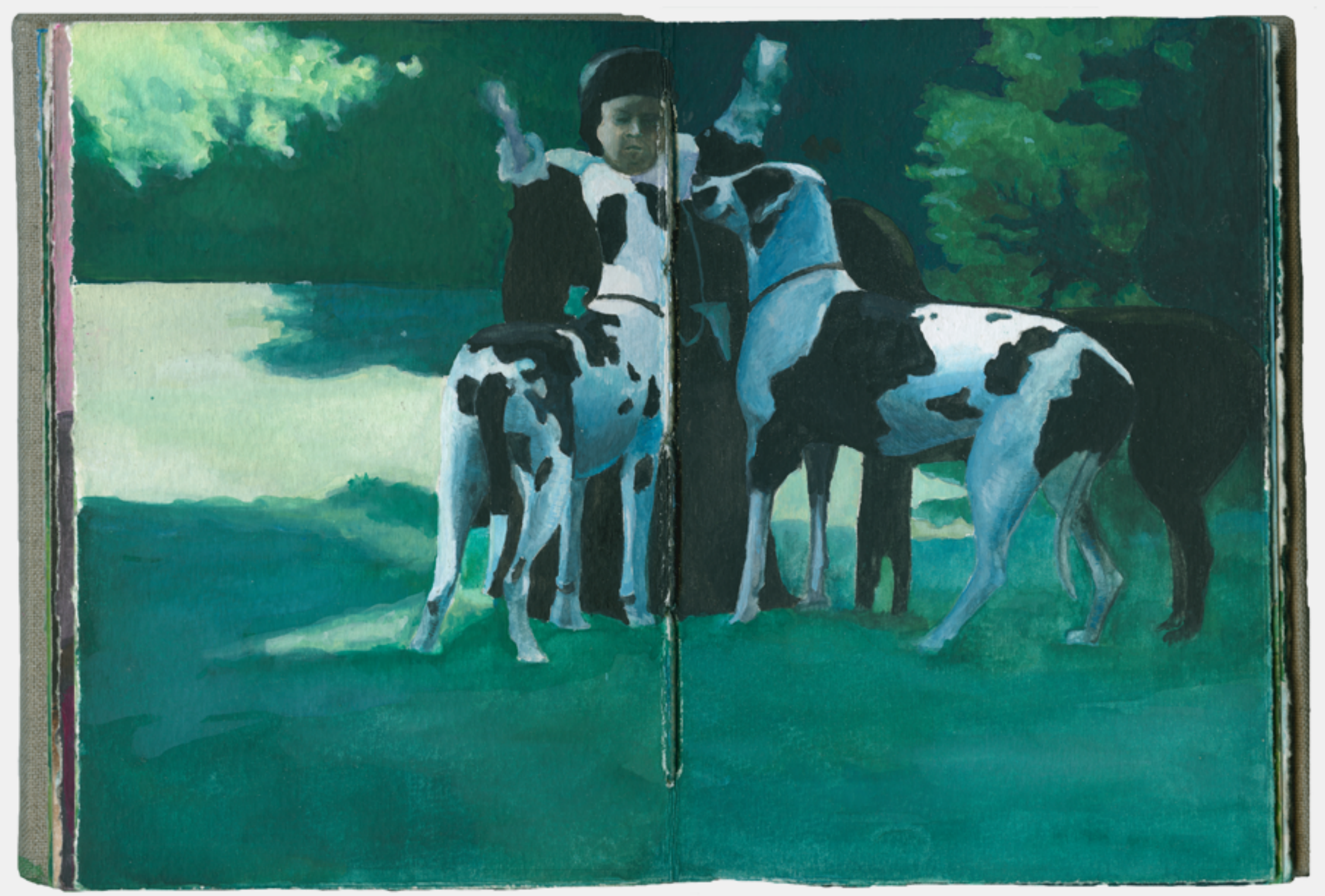

2013

Guache sobre papel

$15 \times 21 \mathrm{~cm}$ 


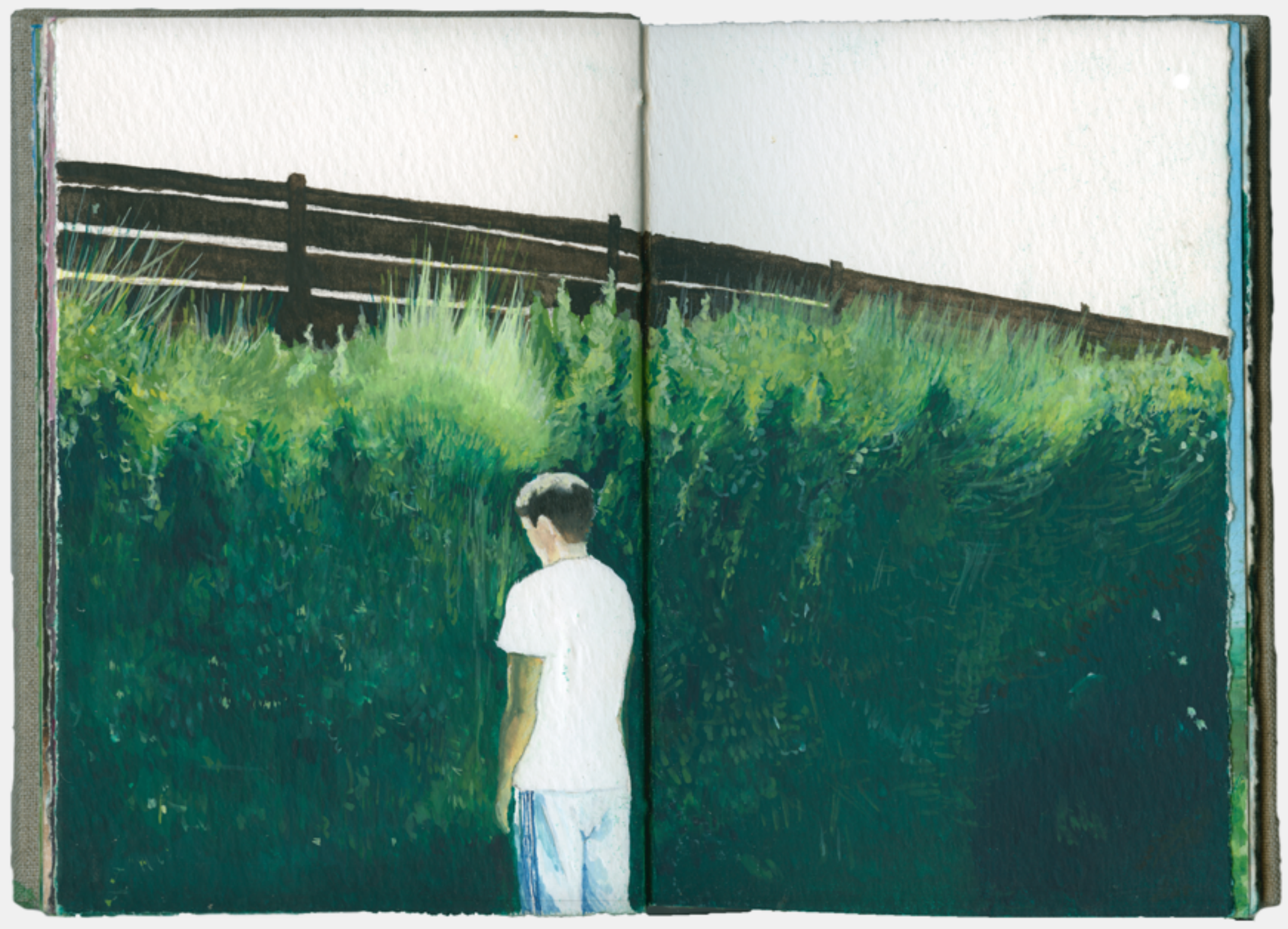

2013

Guache sobre papel 


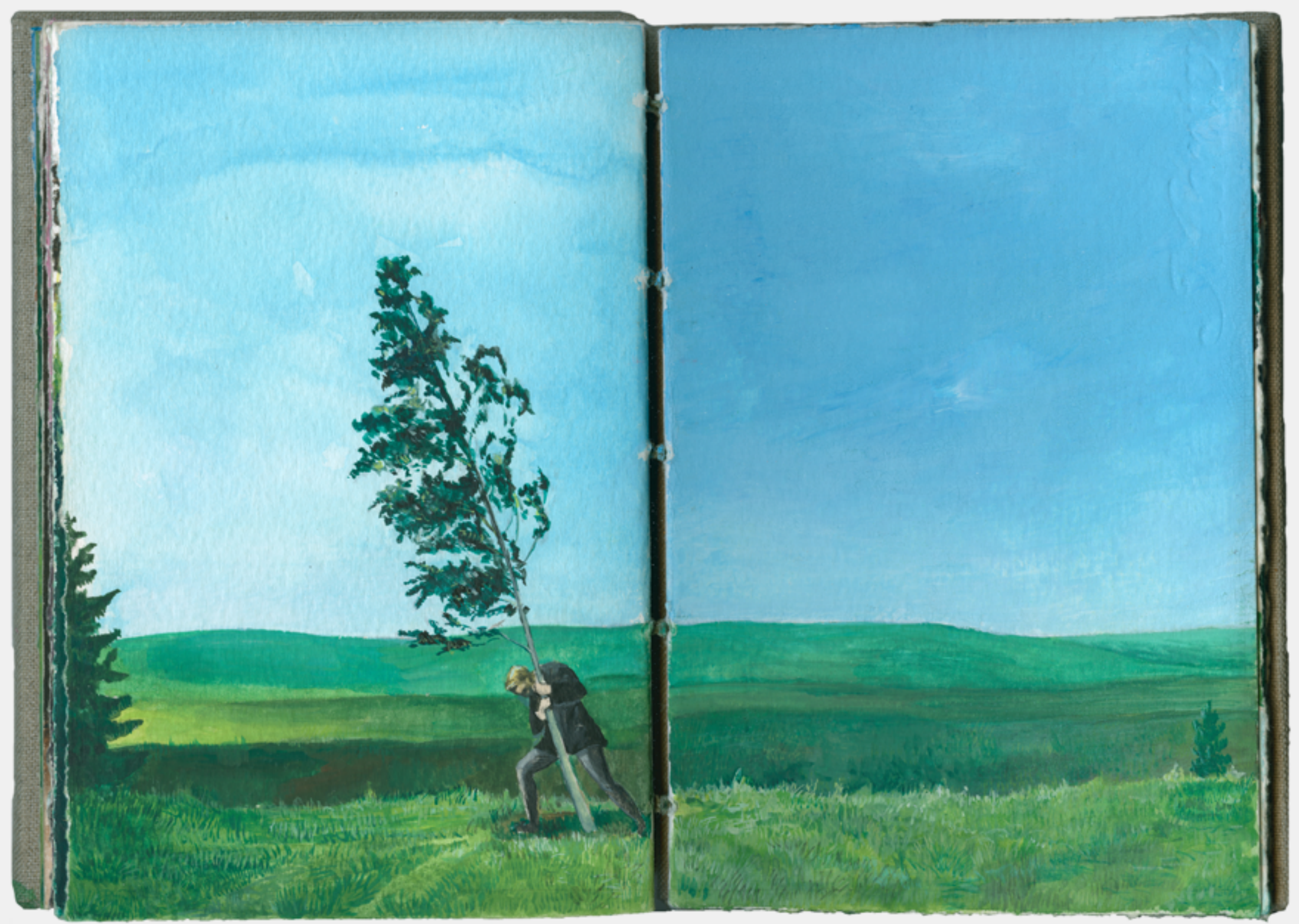

2013

Guache sobre papel 


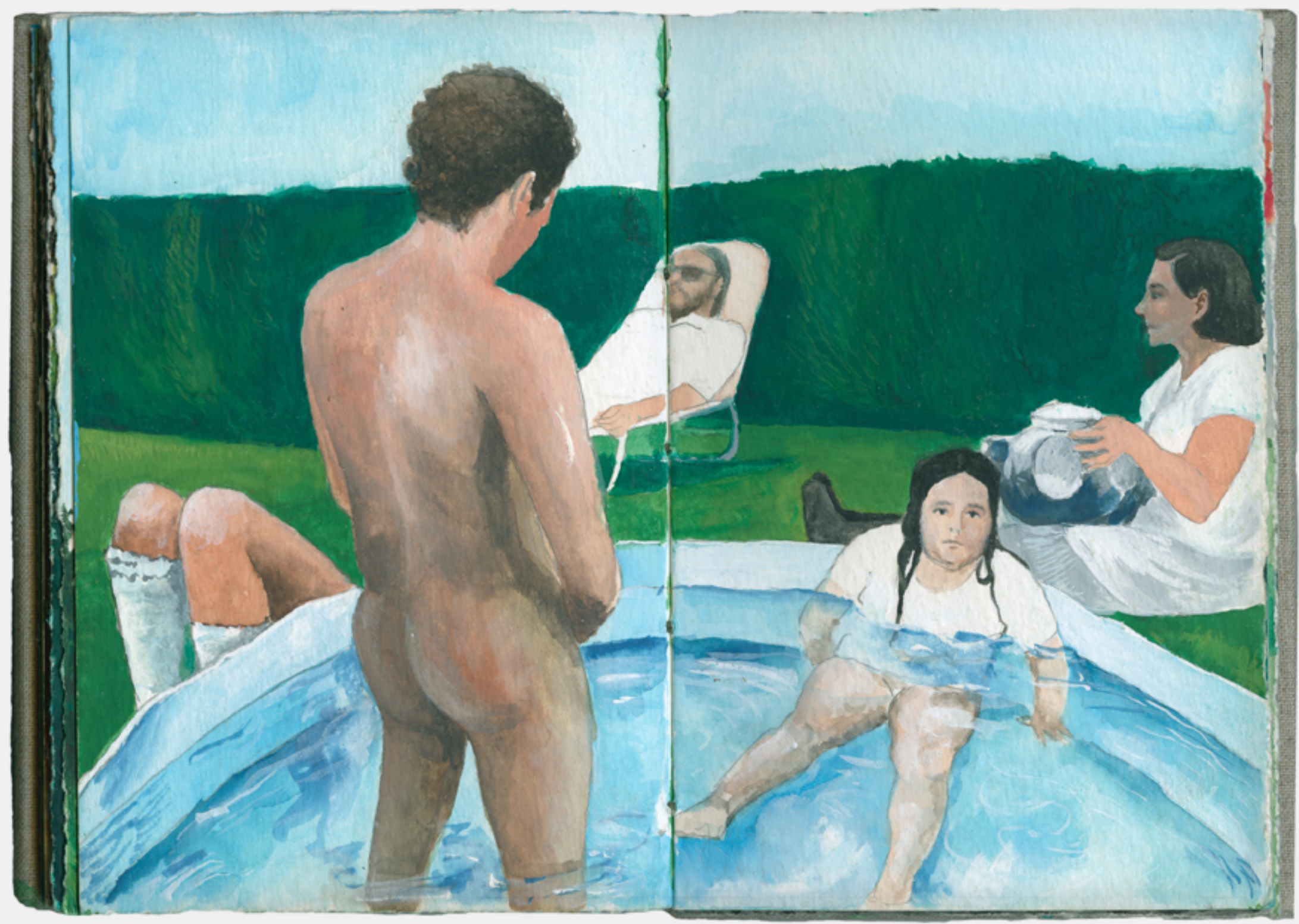

2013

Guache sobre papel 


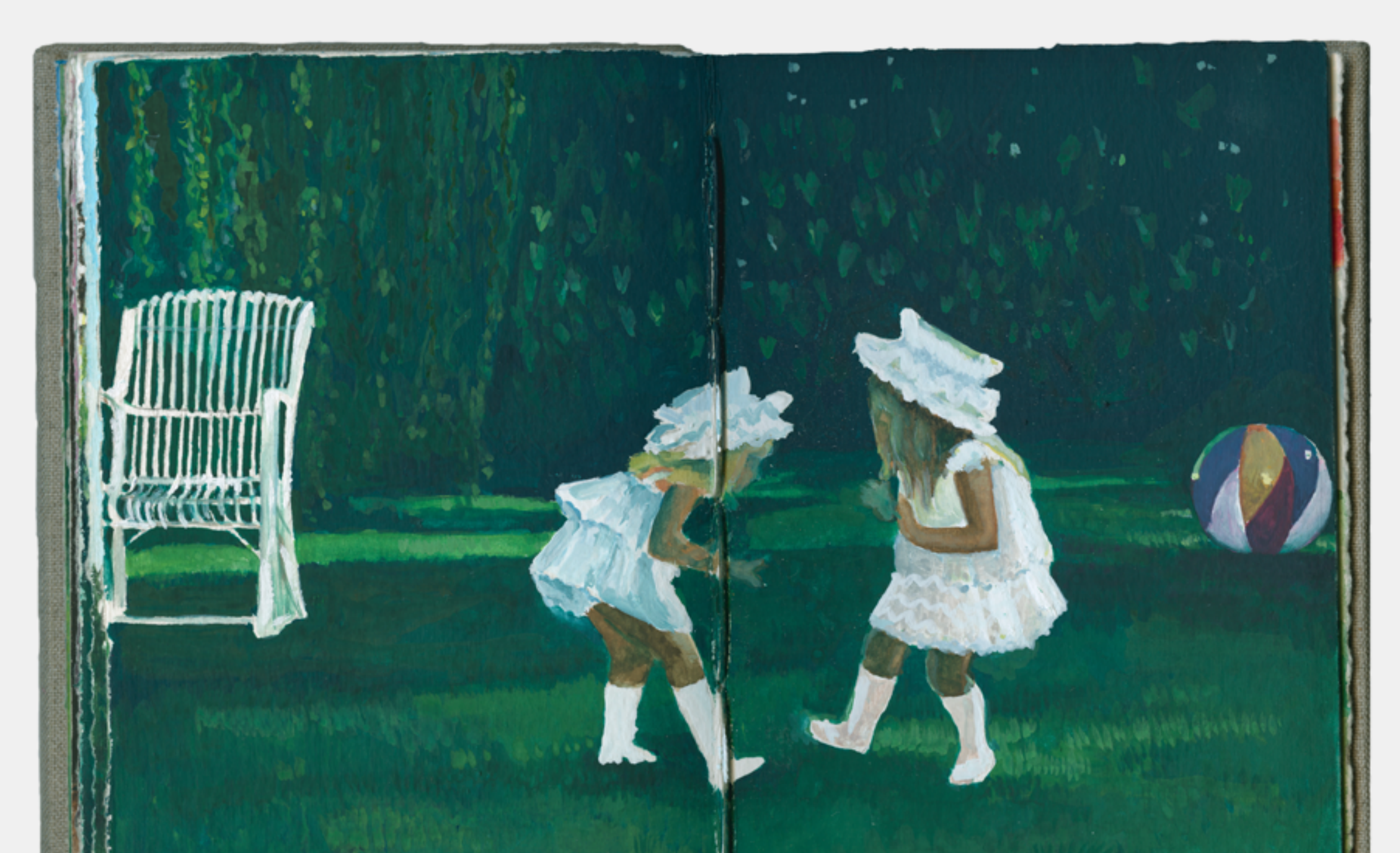

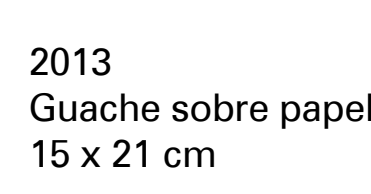




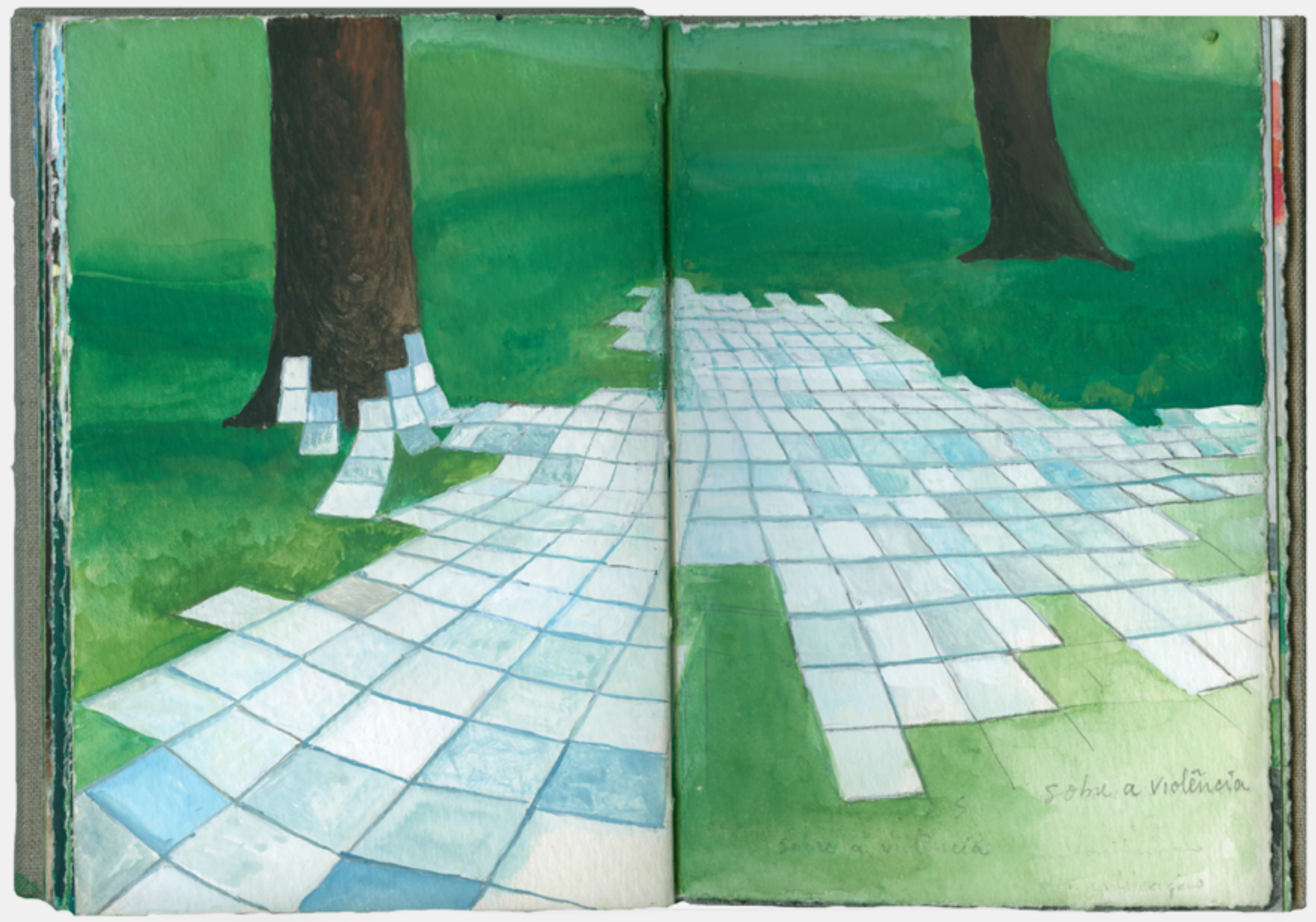

2013

Guache sobre papel $15 \times 21 \mathrm{~cm}$ 


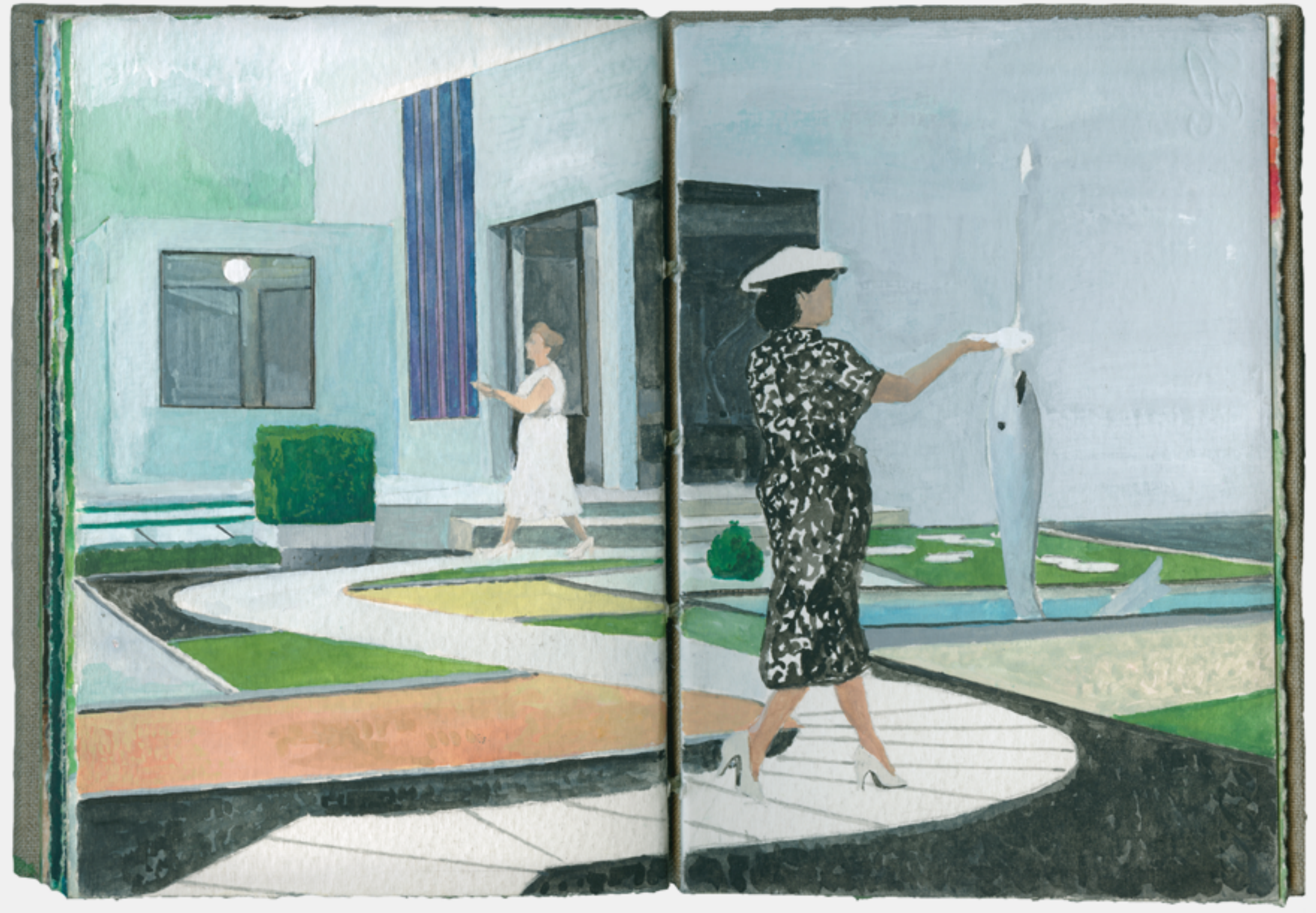

2013

Guache sobre papel

$15 \times 21 \mathrm{~cm}$ 


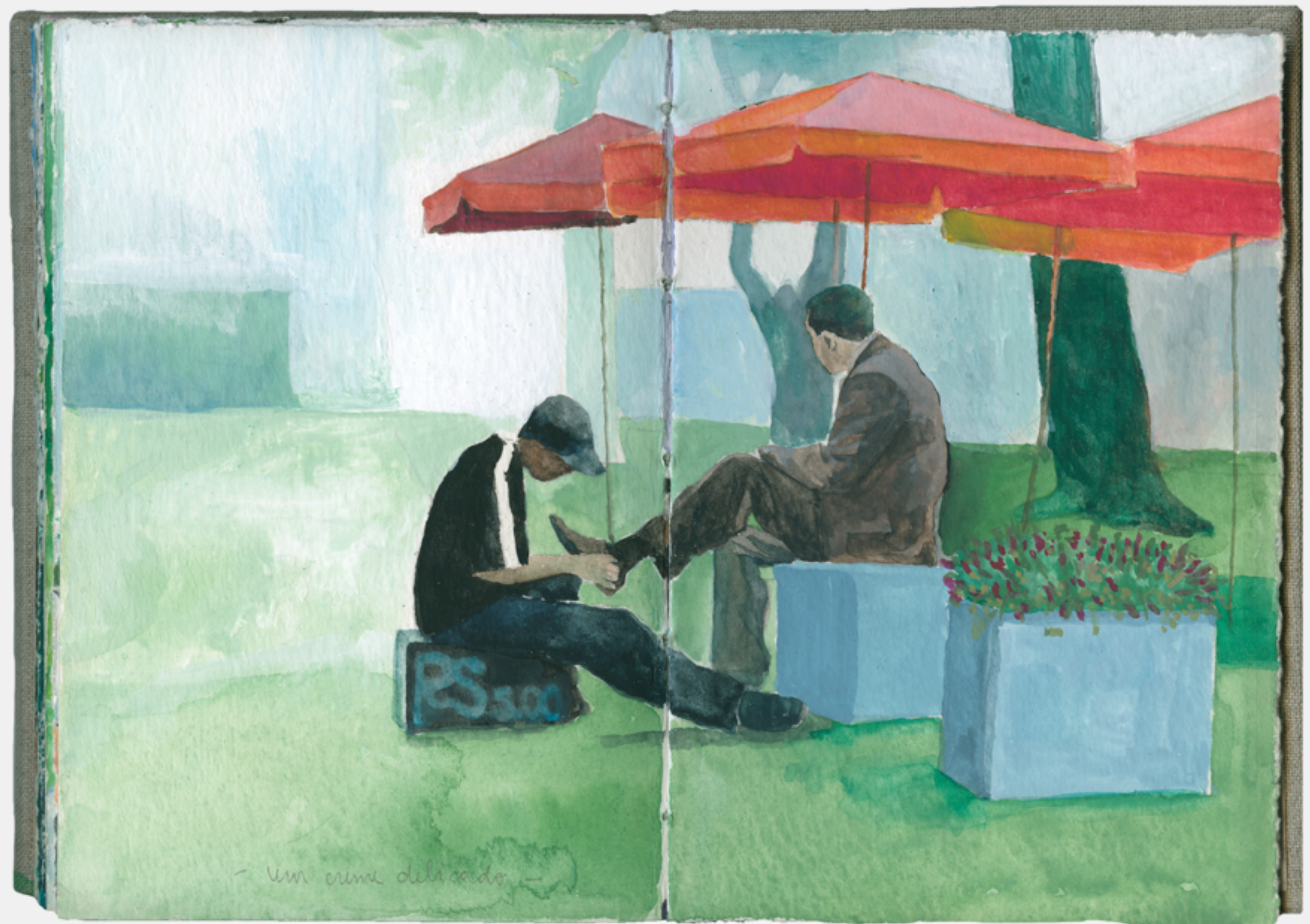

2013

Guache sobre papel 


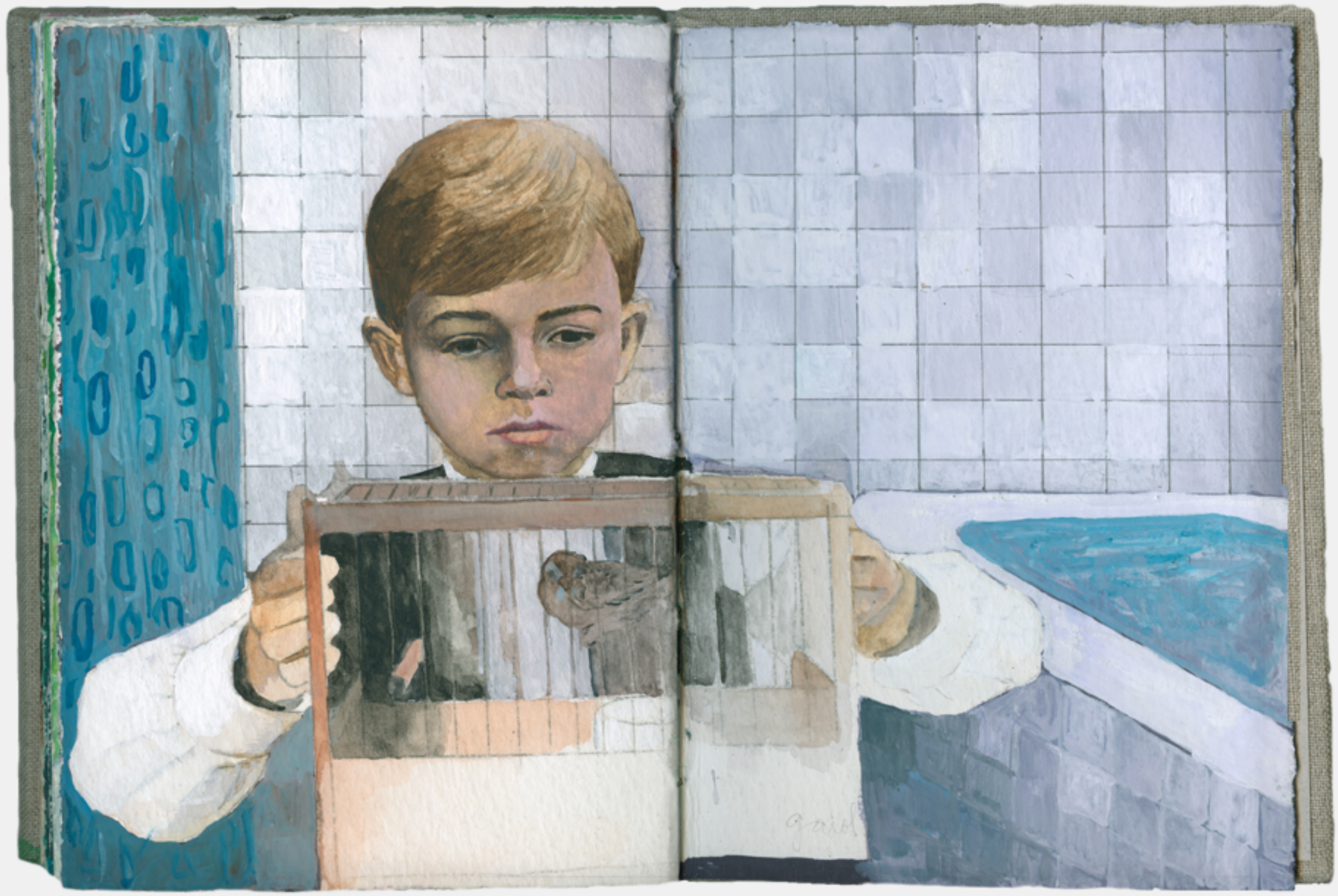

2013

Guache sobre papel 


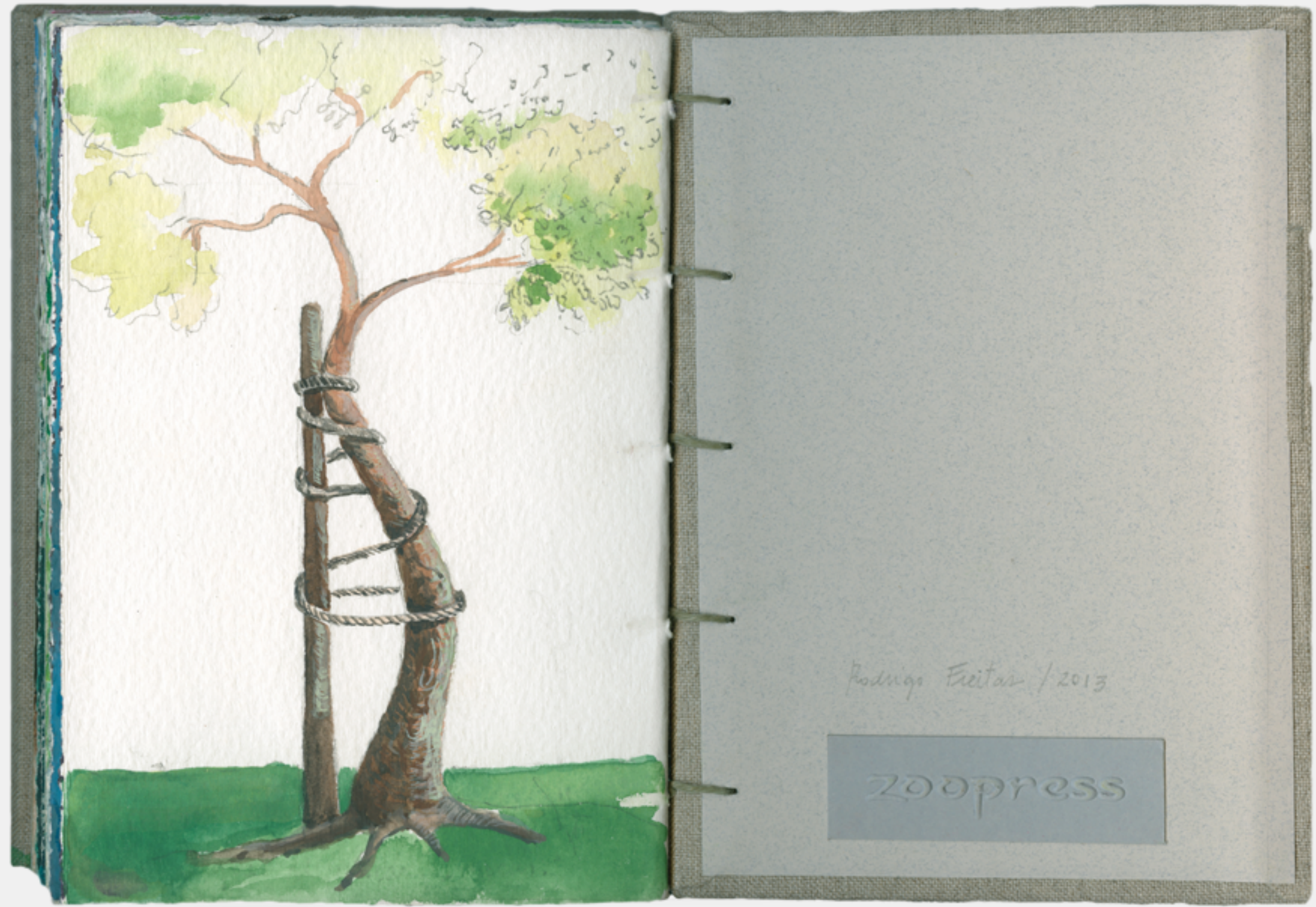

2013

Guache sobre papel $15 \times 21 \mathrm{~cm}$ 